\section{Urinary melatonin levels in children with atopic dermatitis and healthy controls}

Dwi Ratna Adisty, Iskandar Zulkarnain, Diah Mira Indramaya

Department of Dermatology and Venereology, Universitas Airlangga, Dr. Soetomo Teaching Hospital, Surabaya, Indonesia

\begin{abstract}
Melatonin an important immunomodulatory molecule in allergic diseases. Melatonin also plays a role in several body systems including to regulate circadian rhythms because of its role to cause drowsiness. Research shows in the case of atopic dermatitis (AD) circadian production of melatonin is reduced compared to healthy controls. This study aimed to investigate the differences of urinary melatonin levels between children with $\mathrm{AD}$ and healthy controls, and its relationship with disease severity. A cross sectional study was conducted in pediatric dermatology division of our outpatient clinic. Severity of AD was determined by using the instruments Scoring Atopic Dermatitis (SCORAD). Urinary melatonin levels were measured by Enzyme-linked immunosorbent assay (ELISA). The urinary melatonin levels in AD group were not significantly lower than in healthy controls $(\mathrm{P}=0.98 \mathrm{P}<0.05)$ but the means show lower levels of urinary melatonin levels in AD group (486.73 \pm 292.13 $\mathrm{pg} / \mathrm{ml}, 611.51 \pm 280.45 \mathrm{pg} / \mathrm{ml}$, respectively). There were no significant association between urinary melatonin levels and disease severity $(\mathrm{P}>0.05)$ but there's a tendency of decreased urinary melatonin with increased the severity of AD.
\end{abstract}

\section{Introduction}

$\mathrm{AD}$ is caused by abnormalities in skin inflammatory process that are multifactorial, chronic, and relapse-recurrence. Oxidative stress stimulates the inflammatory response that causes allergic diseases such as AD, allergic rhinitis, and asthma. The severity of the disease, coupled with stress associated with chronicity of the disease and impairment of the immune response, results in sleep disturbance in patients with AD. ${ }^{1}$ Sleep disorders caused by pruritus in $\mathrm{AD}$ patients can cause physical and mental fatigue, mood swings, and decreased concentration. ${ }^{2}$

Research shows that in the case of AD circadian production (nighttime) of melatonin is reduced. ${ }^{3}$ Melatonin bridges the homeostatic conditions between the brain and the immune system. Gamma interferon increases melatonin synthesis. AD patients have low gamma interferon levels so that melatonin synthesis is reduced and results in sleep disturbance in $\mathrm{AD}$ patients. The use of melatonin for sleep-deprived AD patients is expected to be helpful because of the ability of melatonin to regulate the sleep phase and other functions that can inhibit proinflammatory cytokines and increase the production of anti-inflammatory cytokines where the balance of these cytokines is impaired in patients with AD.

Research on urinary melatonin in $\mathrm{AD}$ patients has not been widely performed and the results of these studies are also controversial. Previous observations led us to conduct research to measure urinary melatonin levels in $\mathrm{AD}$ patients compared with control children.

\section{Materials and Methods}

Observational analytical research with cross sectional was aimed to compare urinary melatonin levels in $\mathrm{AD}$ patients compared to healthy controls. Sampling of the study was conducted on a consecutive basis from patients who met the criteria for receiving samples up to the number of samples met. Written informed consent was ethically approved by ethical commitee of Dr. Soetomo general hospital. Study was conducted on 44 samples consisting of $22 \mathrm{AD}$ samples and 22 control samples. All samples meet the requirements and are willing to participate in the research by signing information for consent, informed consent.

\section{Results}

The results showed that the average urinary melatonin content in the $\mathrm{AD}$ group was $486.73 \pm 292.13 \mathrm{pg} / \mathrm{ml}$ and in the control group was $611.51 \pm 280.45 \mathrm{pg} / \mathrm{ml}$ (Figure 1). Based on t-test of 2 unpaired samples, there was no statistically significant difference for urinary melatonin levels between atopic dermatitis group and control group ( $\mathrm{p}$ $=0,98)$.

The results showed that the mean of urinary melatonin levels in the $\mathrm{AD}$ patients with severe severity was $144.38 \pm 62.44 \mathrm{pg} /$ $\mathrm{ml}$, the degree of moderate severity was $430.8 \pm 134.99 \mathrm{pg} / \mathrm{ml}$, and the mild severity was $874.58 \pm 98.70 \mathrm{pg} / \mathrm{ml}$ (Figure 2).
Correspondence: Dwi Ratna Adisty, Department of Dermatology and Venereology, Universitas Airlangga, Dr. Soetomo Teaching Hospital, Surabaya, Indonesia. Prof. Dr. Moestopo 47, Surabaya, Indonesia.

Tel.: +6281803536569.

E-mail: nanaadisty@gmail.com

Key words: atopic dermatitis, children, melatonin urine.

Contributions: the authors contributed equally.

Conflict of interest: the authors declare no potential conflict of interest.

Funding: none

Received for publication: 1 February 2019. Accepted for publication: 13 February 2019.

This work is licensed under a Creative Commons Attribution-NonCommercial 4.0 International License (CC BY-NC 4.0).

(C) Copyright D.R. Adisty et al., 2019

Licensee PAGEPress, Italy

Dermatology Reports 2019; 11(s1):8064

doi:10.4081/dr.2019.8064

\section{Discussion}

Results showed that the mean urinary melatonin content in the $\mathrm{AD}$ group was lower than in the control group, although there was no statistically significant difference $(p=0.98)$. This result is consistent with previous studies which stated that serum melatonin levels in AD patients were lower than in the control group. ${ }^{4}$ Melatonin affects the synthesis of IFN- $\gamma$, and, although there is no significant data on the relationship between melatonin and $\mathrm{AD}$, it has been reported that IFN- $\gamma$ is associated with serum levels of melatonin and AD. Generally, IFN- $\gamma$ improves melatonin synthesis. AD patients show lower IFN- $y$ production and potentially lead to reduced release of melatonin and, in turn, may contribute to sleep disturbance and further stress in patients with AD. ${ }^{1}$ Research showed that the metabolite rate of nocturnal melatonin (6-sulfatoxymelatonin) in patients with $\mathrm{AD}$ was slightly higher than controls. Higher levels of melatonin are associated with better sleep efficiency, less fragmentation of sleep, and milder degrees of illness. ${ }^{3}$ The explanation of these results is the mechanism of increased melatonin compensation to improve sleep disorders in $\mathrm{AD}$ patients, and those who respond to these reactions will have an effect on elevated levels of melatonin on 


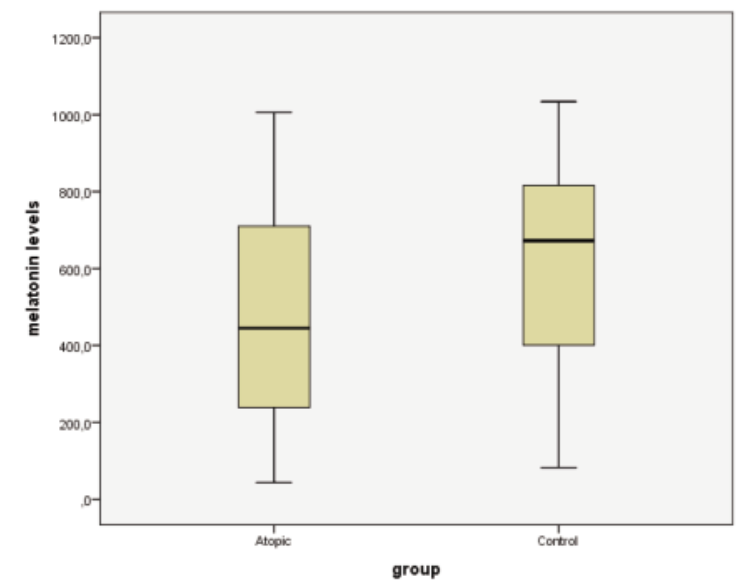

Figure 1. Boxplot of average urinary melatonin levels in atopic and control groups.

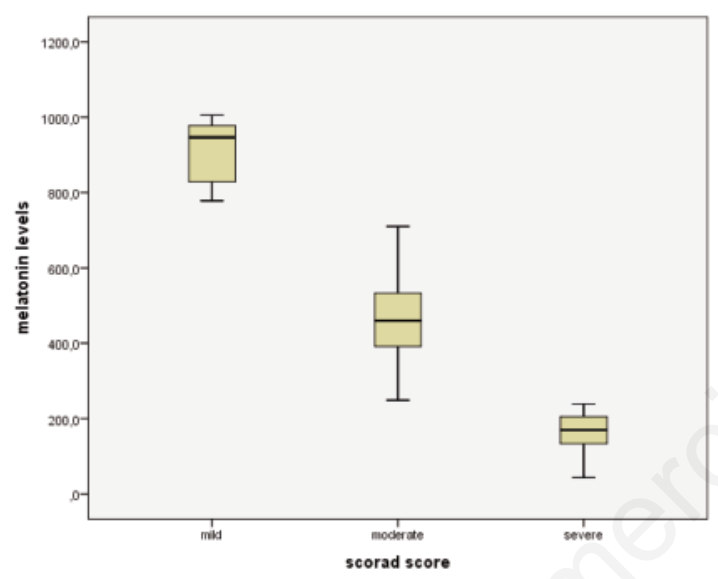

Figure 2. Boxplot of average urinary melatonin levels based on degree of severity.

examination. The levels of urinary melatonin decreases as the severity of $\mathrm{AD}$ is worsening. Research on the provision of melatonin supplements in AD showed results that with the administration of mela-

\section{Conclusions}

The urinary melatonin levels in $\mathrm{AD}$ group were not significantly lower than in healthy controls. There was no significant association between urinary melatonin levels and disease severity but the tendency of decreased urinary melatonin levels in accordance with increasing the severity of $\mathrm{AD}$.

\section{References}

1. Marseglia L, D’angelo G, Manti S, Salpietro C, Arigo T, Barberi I. Melatonin and atopy: role in atopic dermatitis and ashtma.Int. J. Mol. Sci. 2014; 15: 13482-93.

2. Chang YS, Chiang BL. Mechanism of sleep disturbance in children with atopic dermatitis and the role of the circadian rhythm and melatonin. Int $\mathrm{J}$ Mol Sci 2016; 17: 462.1-11.

3. Schwarz W, Birau N, Hornstein OP. Alterations of melatonin secretion in atopic eczema. Acta Derm Venereol 1988; 68: 224-9.

4. Munoz-Hoyos A, Espın-Quirantes C, Molina-Carballo A, Uberos J, Contreras-Chova F, Narbona-Lopez E, Gutierrez-Salmeron MJ. Neuroendocrine and circadian aspects (melatonin and b-endorphin) of atopic dermatitis in the child. Pediatr Allergy Immunol 2007; 18: 679-86.

5. Chang YS, Lin MH, Lee JH, Lee PL, Dai YS, et al. Melatonin supplementation for children with atopic dermatitis and sleep disturbance: A randomized clinical trial. JAMA Pediatr. 2016; 170: 35-42. tonin can improve SCORAD averages become lighter, so it can be concluded that the lower SCORAD, melatonin levels is also higher. ${ }^{5}$ 